or subsequent to a previous delivery by the natural means, as I cannot call to mind ever reading of such a case.

Baroda, Bombay Presidency.

\section{ON THE MORE EXTENSIVE SPLINTERING OF ONE THAN THE OTHER TABLE, IN CERTAIN FRACTURES OF THE SKULL.}

\section{B Y G I L B E R T K I R K E R, M.D., M.R.C.S. E.} LATE OF THE STAFFORD-HOUSE HOSPITAL, ADRIANOPLE.

IT has long been observed that in depressed and punctured fractures of the skull, one table, ordinarily the inner, is more extensively splintered than the other. To account for this occurrence many experiments have been made and various theories brought forward; but, as far as I know, the true explanation has never yet been offered.

Because, in fractures of the skull, the breaking force is always applied to the outside, and rarely also to the inside; and because the more extensive splintering is just as often in the inner and as rarely in the outer table; therefore peculiar conditious have been sought for in the inner to account for it.

When it was believed that this kind of splintering only took place in the inner table, it was said to be due to that plate of bone being more brittle than the outer. It is now, however, known to take place in both; besides, as I shall afterwards show, greater brittleness, instead of accounting for its occurrence, should lead one to expect its non-occurrence. It has been accounted for by stating that the force is transmitted to a wider area as the body causing the fracture passes into or through the bone, carrying its substance before it. This theory, while partially explaining its presence in the case of blunt fracturing bodies, fails entirely, as Mr. Erichsen has shown, when the body causing the fracture is sharp, like a nail. Again, by Mr. Erichsen it is considered to be due to "the direction of the fracturing force and the loss of the momentum in the breaking body." I am certain, and Mr. Erichsen quotes a case to prove, that the more extensive splintering takes place in the inner table when the breaking body travels inwards, and in the outer when it travels outwards; in other words, the more extensive splintering occurs in the table last affected by the fracturing force. There is also no doubt that the loss of momentum in the breaking body increases the splintering. Still this explanation is incomplete, for it does not account for the possible non-occurrence of more extensive splintering of the table last affected in certain cases.

Everyone who has made a post-mortem examination of the head must have noticed that in making the holes in the vault for fastening it to the base, if the part of the bone to be perforated was placed firmly on a board, the awl, in being driven through, caused little splintering of the lamina of bone last penetrated. I have also demonstrated, by shooting bullets through the bones of the skull, that the splintering round the exit opening, by certain arrangements, can be diminished, and I believe could be prevented altogether if the arrangements were perfect. Thus, I took the two parietal bones of a skull : for one I carved out a bed in a thick board to fit its convex side, retaining it in its place, and filling up the spaces between the bone and the wood, with plaster-of-Paris; and the other I secured in a hole which went completely through another board. I then shot a pistol, from the same distance, at the concave side of each. Through the first the bullet did not pass, but embedded itself in the bone, raising four little splinters where it would have emerged, and opposite to which the plaster-of-Paris and wood had yielded. Through the second the bullet passed, shelving the circumference of the exit-opening, by carrying away small splinters, making large splinters more externally, and fissuring the bone. I then thought I could still lessen the splintering round the exit-opening if I substituted bone for the wood and plaster-of-Paris. For this purpose I took two pieces of parietal bones; by filing fitted (as accurately as I could) the convexity of one into the concavity of the other, and fastened them together by wooden pegs. Through these I shot a bullet, again aiming at the concave side. The result in this case was more satisfactory, for the exit-opening in the one first penetrated was very little splintered, its circumference being only partially shelved round. The little splintering present was due to the inequalities between the opposed surfaces of the bones. It is impossible to remove entirely these inequalities, but the more exactly the surfaces of the bones come together the less will be the splintering. I have also, by driving an awl forcibly through the bones of the skull with a mallet, produced very little or a great deal of splintering where the point of the awl emerged, according as the bones were or were not firmly supported.

What, then, is the explanation of the facts that in some depressed and punctured fractures of the skull, including all those occurring during life, there is markedly more extensive splintering of one table than the other; while in others it exists to only a slight degree, and even may not take place at all? I answer: the comparative want of support, in the former, of the table last affected by the fracturing force, and its presence to a creater derree in the latter.

If the experience of every-day life had been bronght to bear on this subject, it must certainly have been understood long ago. Who has not found out that when a nail is driven through two boards, there is splintering of the wood when the point of the nail emerges from the second, but none where it emerges from the first? Or who has not seen a carpenter, when abont to make an anger-hole in a planed board, attach a piece of wood to its under-surface, to prevent the auger making splinters at the lower end of the hole?

Although in these fractures of the sknil the unequal splintering of the tables is due to the fracturing force first attacking the table, supported by the other and the intervening diploe, and afterwarls that, whthont any firm support, it varies under certain circumstances. 1. When the breilking body is blunt it carries the bone before it, and affects a laroer area of the second than the first table. 2. The greater the momentum of the breaking body the less is the splintering. This is probably owing to the particles of bone in the course of the breaking body having been broken ofl from their connexions with the surrounding particles hefore they had communicated to the latter much of the fracturing force. 3 . It has commonly been said that brittleness is a cause of splintering, but to me it appears that its influence is in the oppo. site direction. In brittle substances the conmexions between the component particles are readily broken, and when such a substance is acted on by a breaking body the particles affected have a greater tendency to sever their connexions with neighbouring ones than communicate to them the fracturing force. Nothing could be more brittle, were it possible to make it, than a wall of sand; yet, if a cannon-ball passed through it, there would be no cracking of the wall: the sand only in the course of the ball would be carried away. Belfast.

\section{A CASE OF POISONING BY CORROSIVE SUBLIMATE.}

\section{BY T. WEMYSS BOGG, M.B. LOND., M.R.C.P.}

IN May, 1873, I was requested by the coroner of the district in which $I$ then resided to make a post-mortem examination of the body of an infant in the neighbouring village of $\mathrm{D}-$. The reason for ordering the inquest was simply that the child had died without medical attendance, and that it was illegitimate, its mother being for some years a widow. There was, however, no suspicion of foul play.

On examining the body thirty-three hours after death, I found a full-grown male child, not apparently emaciated, presenting cadaveric congestion of the back, loins, front of thighs, and feet, and blueness of the dorsum of the penis. The navel-string had separated, and there was a black stool in the napkin. The only history I then learned was that the child had lived nine days, had latterly vomited all its food, and finally died in convulsions. In this, of course, there was nothing inexplicable on the supposition of improper feeding, except the stool, which might easily have been taken for a dark, bilious evacuation. The lips, however, were dry and black, the gums white, and the tongue covered with dark-brown fur. On section, the right heart and venous system were found distended with blood, the lungs congested, the left one being partly in a state of atelectasis. Liver dark, with congestion both at centre and circumference of lobules. Gall. 